\title{
Androgen-mediated sex bias impairs efficiency of leukotriene biosynthesis inhibitors in males
}

\author{
Simona Pace, ${ }^{1}$ Carlo Pergola, ${ }^{1}$ Friederike Dehm, ${ }^{1,2}$ Antonietta Rossi, ${ }^{2}$ Jana Gerstmeier, ${ }^{1}$ Fabiana Troisi, ${ }^{1}$ Helmut Pein, ${ }^{1}$ \\ Anja M. Schaible, ${ }^{1}$ Christina Weinigel, ${ }^{3}$ Silke Rummler, ${ }^{3}$ Hinnak Northoff, ${ }^{4}$ Stefan Laufer, ${ }^{5}$ Thorsten J. Maier, ${ }^{6,7}$ \\ Olof Rådmark, ${ }^{8}$ Bengt Samuelsson, ${ }^{8}$ Andreas Koeberle, ${ }^{1}$ Lidia Sautebin, ${ }^{2}$ and Oliver Werz ${ }^{1}$
}

\begin{abstract}
'Department of Pharmaceutical/Medicinal Chemistry, Institute of Pharmacy, Friedrich-Schiller-University Jena, University Hospital Jena, Jena, Germany. ${ }^{2}$ Department of Pharmacy, School of Medicine, University of Naples Federico II, Naples, Italy. ${ }^{3}$ Institute of Transfusion Medicine, University Hospital Jena, Jena, Germany. ${ }^{4}$ Institute for Clinical and Experimental Transfusion Medicine, University Medical Center Tuebingen, and ${ }^{5}$ Department of Medicinal Chemistry, Pharmaceutical Institute, University Tuebingen, Tuebingen, Cermany. ${ }^{6}$ Aarhus University, Department of Biomedicine and Center for Study and Prevention of Neurodegenerative Inflammation (NEURODIN), Aarhus, Denmark. ${ }^{7}$ Department of Anesthesia, Intensive Care Medicine and Pain Therapy, University Hospital Frankfurt, Frankfurt am Main, Germany. ${ }^{8}$ Department of Medical Biochemistry and Biophysics, Division of Physiological Chemistry II, Karolinska Institutet, Stockholm, Sweden.
\end{abstract}

\begin{abstract}
Proinflammatory leukotrienes (LTs) are produced by 5-lipoxygenase (5-LO) aided by 5-LO-activating protein (FLAP). LT biosynthesis inhibitors are currently under clinical investigation as treatments for respiratory and cardiovascular diseases. Here, we have revealed a sex bias in the efficiency of clinically relevant LT biosynthesis inhibitors, showing that their effects are superior in females. We found that androgens cause these sex differences by impeding the LT-biosynthetic 5-LO/FLAP

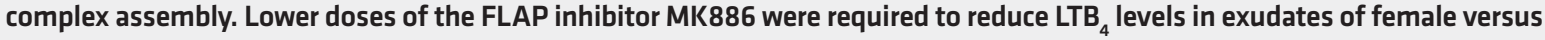
male mice and rats. Following platelet-activating factor-induced shock, MK886 increased survival exclusively in female mice, and this effect was abolished by testosterone administration. FLAP inhibitors and the novel-type 5-LO inhibitors licofelone and sulindac sulfide exhibited higher potencies in human blood from females, and bioactive 5-LO/FLAP complexes were formed in female, but not male, human and murine leukocytes. Supplementation of female blood or leukocytes with $5 \alpha$-dihydrotestosterone abolished the observed sex differences. Our data suggest that females may benefit from anti-LT therapy to a greater extent than males, prompting consideration of sex issues in LT modifier development.
\end{abstract}

\section{Introduction}

Leukotrienes (LTs) are potent lipid mediators of inflammation and immunity, with established roles in asthma and allergic rhinitis, but also in atherosclerosis, cardiovascular disease, and cancer $(1,2)$. For LT biosynthesis, arachidonic acid (AA) is released from phospholipids by cytosolic phospholipase $\mathrm{A}_{2}\left(\mathrm{cPLA}_{2}\right)$ and delivered to 5-lipoxygenase (5-LO) by the nuclear membrane-bound 5-LOactivating protein (FLAP) for conversion to 5-hydro(pero)xyeicosatetraenoic acid (5-H[p]ETE) and then to $\operatorname{LTA}_{4}$ (2). The epoxide LTA $_{4}$ can be metabolized to LTB ${ }_{4}$ or to cysteinyl-LTs (cysLTs), which induce leukocyte activation or confer smooth muscle contraction and vascular leakage, respectively (1). In order to access liberated $\mathrm{AA}$ in the cell, 5-LO translocates to the nuclear membrane, binds via its C2-like domain to phosphatidylcholine, and assembles a dynamic complex with FLAP and AA, which is temporally regulated and considered pivotal for LTA $_{4}$ biosynthesis (3-7).

Sex differences in the incidence of LT-related diseases (e.g., severe asthma, autoimmune diseases, and allergic rhinitis, which

\section{Related Commentary: p. 2895}

Authorship note: S. Pace and C. Pergola contributed equally to this work. Conflict of interest: The authors have declared that no conflict of interest exists. Submitted: January 17, 2017; Accepted: April 28, 2017. Reference information: / Clin Invest. 2017;127(8):3167-3176. https://doi.org/10.1172/JCI92885. all dominate in females) are evident (8-10), and sex is recently emerging as a key variable for the regulation of various lipoxygenases. Thus, sex differences in LT biosynthesis exist in human neutrophils and monocytes as well as in murine peritoneal macrophages (PMs), and androgens downregulate LT formation by affecting 5-LO cell biology (11-13). In zymosan-induced peritonitis, higher LT biosynthesis in female mice in vivo was connected to increased vascular permeability and neutrophil recruitment versus male animals (13). Moreover, a sex-specific attenuation of atheroma formation was observed in dual 5-LO and 12/15-LO KO mice (14), and deletion of the $\mathrm{LTB}_{4}$ receptor $B L T 1$ protected female, but not male, mice in the platelet-activating factor-induced (PAFinduced) shock model (15). Recently, sex differences in resolution of inflammation (cantharidin-induced skin blisters in healthy humans) were connected to higher D-resolvin formation in female neutrophils (16) and estradiol was shown to reduce the biosynthesis of lipoxin $\mathrm{A}_{4}$ (produced by $15-\mathrm{LO}$ and $5-\mathrm{LO}$ ), accounting for attenuated corneal epithelial wound healing in female mice (17). Together, these observations call for consideration of sex issues in evaluating the therapeutic potential of LT biosynthesis modifiers.

Clinically relevant LT-modifying agents include inhibitors of FLAP or 5-LO, which are currently under clinical investigation as candidates for the treatment of respiratory and cardiovascular diseases $(18,19)$. Despite intensive research, only the direct 5-LO inhibitor zileuton entered the market as an antiasthmatic drug, while other compounds failed in clinical trials due to lack of efficacy 


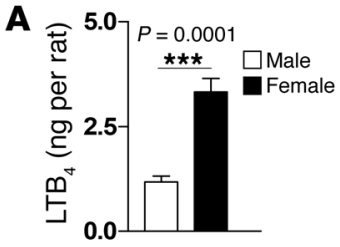

C

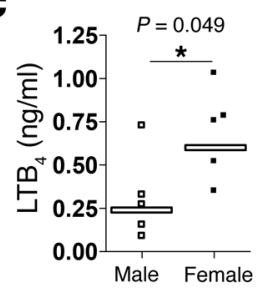

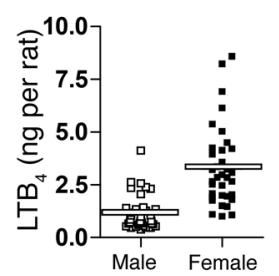

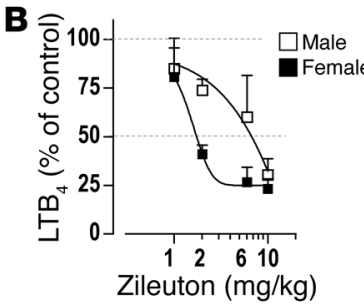

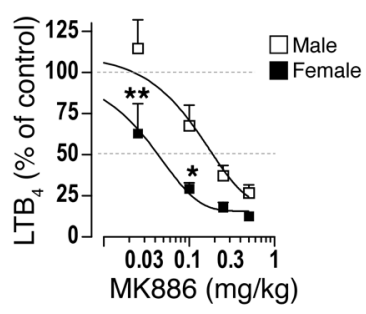

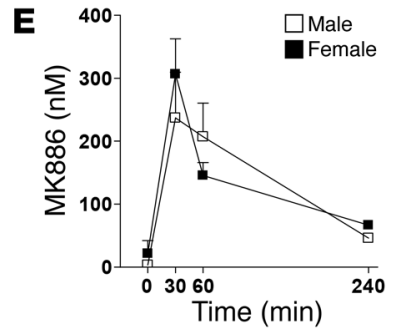

Figure 1. Sex differences in the production of LTB $_{4}$ and in the potency of LT biosynthesis inhibitors in vivo. (A) LTB levels in the thoracic cavity 2 hours after $\lambda$-carrageenan injection in male and female rats. $n=35$ ( 5 rats/sex in 7 experiments); unpaired 2-tailed $t$ test. Data passed normality test. ${ }^{* * *} P<0.001$. (B) Effects of zileuton and MK886 on pleural LTB levels in male and female rats 2 hours after $\lambda$-carrageenan injection. Vehicle or compounds were injected i.p. 30 minutes prior to $\lambda$-carrageenan. Data show percentage of controls, mean $+\mathrm{SEM}$. For $10 \mathrm{mg} / \mathrm{kg}$ zileuton and $0.5 \mathrm{mg} / \mathrm{kg} \mathrm{MK886,} n=10$ (5 rats $/ \mathrm{sex}$ in 2 experiments); for the other doses, $n=5$ ( 5 rats/sex in 1 experiment). The different doses were tested in independent experiments performed side by side with male/female rats and controls. ${ }^{*} P<0.05 ;{ }^{* *} P<0.01$ vs. corresponding males, ANOVA plus Bonferroni. (C) LTB 4 levels in the peritoneal cavity 15 minutes after i.p. zymosan injection in male and female mice. $n=5$ ( 5 mice/sex in 1 experiment); unpaired 2-tailed $t$ test. (D) Mice received $1 \mathrm{mg} / \mathrm{kg}$ MK886 or 0.5 $\mathrm{mg} / \mathrm{kg} 5 \alpha$-DHT or vehicle 30 minutes prior to zymosan injection. LTB $\mathrm{B}_{4}$ levels in the peritoneal cavity of male and female mice were assessed 15 minutes after i.p. zymosan. $n=5$ (5 mice/sex in 1 experiment); ANOVA plus Bonferroni. (E) Plasma levels of MK886 after i.p. injection of $1 \mathrm{mg} / \mathrm{kg}$ in male and female mice at $0,30,60$, and 240 minutes after administration. $n=3$ (3 mice/sex in 1 experiment); no significant differences, ANOVA plus Bonferroni.

or toxicity (19). However, either published studies did not examine sex subgroups separately or sex-related effects were not reported. In fact, a uniform approach is traditionally assumed for women and men in biomedical research (20), although sex may influence both pathophysiology and efficacy of therapeutics as well as pharmacokinetics (e.g., drug metabolism) and pharmacodynamics (21-23). However, the knowledge of the biological basis of sex differences is often insufficient to support the inclusion of sex as a variable in pharmacological studies, and sex differences in drug response have been identified mainly during the pharmacovigilance phase and not during the preclinical and clinical development of compounds. Here, we present preclinical in vivo and in vitro evidence that points out that the effectiveness and potency of certain LT biosynthesis inhibitors depend on the sex, mediated by androgens. Our data show that androgens prevent the tight LT-biosynthetic 5-LO/FLAP complex assembly at the nuclear membrane, possibly explaining why LT biosynthesis inhibitors, which act by inhibiting the 5-LO/ FLAP interaction, are less efficient in males.

\section{Results}

Sex differences in the effects of LT biosynthesis inhibitors in vivo. We analyzed LT biosynthesis in 2 different well-established in vivo models of acute inflammation, rat carrageenan-induced pleurisy and mouse zymosan-induced peritonitis, considering the sex of the animals. In the pleurisy model, the levels of $\mathrm{LTB}_{4}$ in the pleural exudates at 2 hours after carrageenan injection were significantly higher (2.8 times) in females than in males (Figure 1A). Both the iron ligand-type 5-LO inhibitor zileuton, an $N$-hydroxyurea used in asthma therapy $(24)$, and the FLAP inhibitor $\operatorname{MK} 886(25,26)$ were significantly more potent in female than in male rats after carrageenan injection, and $\mathrm{ID}_{50}$ values were 3.9 and 7.2 times higher in males than in females for zileuton and MK886, respectively (Figure 1B).

During acute peritonitis, the levels of $\mathrm{LTB}_{4}(15$ minutes after zymosan injection) were 2.3-fold higher in peritoneal exudates from female versus male mice (Figure $1 \mathrm{C}$ ). Androgens caused rapid (within minutes) impairment of 5-LO product formation in vitro $(11,12)$ and in vivo $(13)$ and may account for the sex bias in the efficiency of LT biosynthesis inhibitors. In fact, pretreatment of female mice, but not of male mice, with $0.5 \mathrm{mg} / \mathrm{kg} 5 \alpha$-dihydrotestosterone ( $5 \alpha$-DHT) (i.p., 30 minutes prior to zymosan) suppressed LTB $_{4}$ levels in the peritoneal exudates (Figure 1D). MK886 (1 mg/kg) was more effective in lowering $\mathrm{LTB}_{4}$ in exudates of female (by $77 \%$ ) versus male mice (by 50\%) (Figure 1D), although MK886 plasma levels (within 240 minutes) were not significantly different between sexes (Figure 1E), implying similar pharmacokinetics.

LTs play a critical role in the lethal shock induced by PAF in mice (27), a suitable model for evaluation of LT biosynthesis inhibitors in vivo. Only $23 \%$ of male and $32 \%$ of female conscious and nonanesthetized mice survived after i.v. injection of $200 \mu \mathrm{g} / \mathrm{kg}$ PAF, without significant difference between the sexes (total: 49 male and female mice each in 9 experiments). Male animals typically died within 20 minutes (95\% CI: 17-23 minutes), which was not significantly different from females (25 minutes; 95\% CI: 20-30 minutes). Administration of zileuton (10 mg/kg, i.p.) or MK886 (0.5 mg/kg, i.p.) selectively improved survival of female mice, but did not provide any advantage in male animals (Table 1). Administration of testosterone propionate $(3 \mathrm{mg} / \mathrm{kg} /$ day, s.c.) for 10 days to female mice did not modify PAF-induced mortality rate (Table 2). However, testosterone abolished the beneficial effects of MK886 (0.5 mg/ kg, i.p.), but not of zileuton (10 mg/kg, i.p.), in female mice (Table 2). Taking 
Table 1. Sex differences in the effects of zileuton and MK886 in the PAF-induced shock of mice

\begin{tabular}{lcc} 
& \multicolumn{2}{c}{$\%$ Survival (survivors/total) } \\
Compound & Male & Female \\
Vehicle $^{\mathrm{A}}$ & $36 \%(4 / 11)$ & $30 \%(3 / 10)$ \\
Zileuton $^{\mathrm{B}}$ & $20 \%(2 / 10)$ & $70 \%(7 / 10)$ \\
MK886 $^{\mathrm{C}}$ & $30 \%(3 / 10)$ & $70 \%(7 / 10)$
\end{tabular}

${ }^{A}$ Vehicle, $500 \mu \mathrm{l}$ of $0.9 \%$ saline solution containing $2 \%$ DMSO. ${ }^{B}$ Zileuton, 10 $\mathrm{mg} / \mathrm{kg}$. ${ }^{\mathrm{C}} \mathrm{MK} 886,0.5 \mathrm{mg} / \mathrm{kg}$, given i.p. 30 minutes prior to i.v. injection of $200 \mu \mathrm{g} / \mathrm{kg}$ PAF.

these data together, LT formation in vivo during acute inflammation is higher in female versus male animals, and the LT biosynthesis inhibitor MK886 is more effective in females.

Sex-related differences in 5-LO product biosynthesis in human blood and effects of direct 5-LO inhibitors. In order to also explore the observed sex differences in humans, we analyzed 5-LO product formation of freshly drawn peripheral blood (i.e., 10 minutes after blood sampling) from male and female healthy donors after treatment with different stimuli. In agreement with previous findings (11), stimulation with LPS together with mediators of inflammation and anaphylaxis (i.e., $N$-formyl-methionyl-leucyl-phenylalanine [fMLP] or PAF) or with $\mathrm{Ca}^{2+}$-ionophore A23187 led to significantly higher 5-LO product formation in female versus male blood (Figure $2 \mathrm{~A})$. Note that the ratio in the formation of individual 5-LO products (i.e., $\mathrm{LTB}_{4}$, its trans isomers, and 5-hydroxyeicosatetraenoic acid [5-HETE]), including the $\mathrm{LTB}_{4}$ metabolite $20-\mathrm{OH}-\mathrm{LTB}_{4}$, between male and female blood was similar (0.41-0.59; Supplemental Table 1 ; supplemental material available online with this article; https:// doi.org/10.1172/JCI92885DS1). 20-COOH-LTB 4 was not detectable. A tendency toward higher 5-LO product formation in female blood was also observed with ionomycin as stimulus (Figure 2A).

In order to assess the efficiency of LT synthesis inhibitors in more detail, analysis of 5-LO product formation evoked by LPS/ fMLP in blood was performed in a larger sample population by liquid chromatography tandem mass spectrometry (LC-MS/ MS) (28), where other AA-derived lipid mediators could also be monitored. After analysis of 35 male and female donors in paired experiments, LPS/fMLP-stimulated 5-LO product formation was 2.6-fold higher in female versus male blood (Figure 2B; 95\% CI: 2.1-3.0). $\mathrm{LTB}_{4}$ and $5-\mathrm{H}(\mathrm{p})$ ETE were the major 5-LO products formed, with constantly higher levels in females (Figure 2B), while only traces of $\mathrm{LTC}_{4}$ were detected (Supplemental Figure 1). Partially higher basal levels of 8-, 11-, 12- and 15-HETE were observed in unstimulated male blood, but this difference vanished after stimulation (Supplemental Figure 1).

Next, the potencies of direct 5-LO inhibitors were evaluated side by side in male and female blood. Zileuton efficiently inhibited 5-LO product formation in blood of both sexes. Although a more pronounced reduction was evident in female versus male blood when absolute amounts of 5 -LO products were considered (Figure $2 \mathrm{C}$ ), no sex difference in the $\mathrm{IC}_{50}$ values was evident after normalization of data as percentage of uninhibited $(=100 \%)$ control (Figure 2D and Supplemental Table 1). In analogy to zileuton, no significant sex bias was observed in the potency of other direct 5-LO inhibitors, irrespective of the molecular mechanism of interference with 5-LO. Thus, the iron ligand-type 5-LO inhibitor BWA4C, the redox-type inhibitor AA-861, the nonredox-type inhibitor ZM230487, and also celecoxib and compound 11a (identified as 5-LO inhibitors; refs. $29,30)$ gave equal $\mathrm{IC}_{50}$ values in male and female blood, with only minor differences in the efficiency at defined concentrations (Supplemental Figure 2 and Supplemental Table 2).

Distinct inhibitors of LT synthesis show higher efficiency in female than in male blood. Release of AA from phospholipids by $\mathrm{CPLA}_{2} \alpha$ and its transfer via FLAP to 5-LO is critical for LT biosynthesis. A specific cPLA 2 a inhibitor (pyrrolidine-1 or RSC-3388) blocked 5-LO product formation in LPS/fMLP-stimulated blood from males and females equally well (Supplemental Figure 2 and Supplemental Table 1). In contrast, the FLAP inhibitor MK886 was significantly more potent in female blood, and total suppression was observed in male blood only at a concentration 10 times higher than in females (30 versus $3 \mu \mathrm{M}$; Figure 3A; Supplemental Table 1). Similarly, the FLAP inhibitor from the quinoline series BAY-X 1005 (31), also known as DG-031 or veliflapon, was significantly more potent in female than in male blood (Figure 3B), and a similar tendency was observed for the FLAP inhibitor MK591, an indole-quinoline hybrid (Supplemental Table 2). Finally, licofelone (a biphenyl pyrrolizine) and sulindac sulfide (Ssi, an indene derivative), which are classified as novel-type 5-LO inhibitors that preferentially interfere with cellular activation of 5-LO by blocking 5-LO translocation to the nuclear membrane where FLAP resides $(32,33)$, were effective only in female blood (Figure 3B and Supplemental Table 1). Together, FLAP inhibitors and distinct novel-type 5-LO inhibitors that block 5-LO nuclear translocation are more efficient in female blood, whereas no sex differences were observed for a cPLA inhib- $_{2}$ itor and various types of direct 5-LO inhibitors.

In agreement with our previous study (11), preincubation of blood from females with $5 \alpha$-DHT (10 or $30 \mathrm{nM}$ ) significantly reduced the synthesis of $5-\mathrm{LO}$ products $\left(\mathrm{LTB}_{4}\right.$, its trans isomers, 20-OH-LTB 4 , and 5-HETE) upon stimulation with A23187 (Supplemental Table 1) or with LPS/fMLP where $5 \alpha$-DHT pretreatment of blood from males caused no change (Figure 3C). The sex hormones $17 \beta$-estradiol $(30 \mathrm{nM})$ and progesterone $(1 \mu \mathrm{M})$ were

\section{Table 2. Testosterone abolishes the effect of MK886 in the PAF-} induced shock of female mice

$\%$ Survival (survivors/total)

$\begin{array}{lcc}\text { Compound } & \text { Control }^{\mathrm{A}} & \text { Testosterone }^{\mathrm{A}} \\ \text { Vehicle }^{\mathrm{B}} & 0 \%(0 / 5) & 0 \%(0 / 15) \\ \text { Zileuton }^{\mathrm{C}} & 40 \%(2 / 5) & 33 \%(5 / 15) \\ \text { Vehicle }^{\mathrm{B}} & 10 \%(1 / 10) & 5 \%(1 / 20) \\ \text { MK886 }^{\mathrm{D}} & 60 \%(6 / 10) & 15 \%(3 / 20)^{\mathrm{E}}\end{array}$

${ }^{A}$ Female mice were treated daily over 10 days with subcutaneous injection of sesame oil ( $100 \mu \mathrm{l}$, control) or testosterone propionate (3 mg/kg). ${ }^{B}$ Vehicle, $500 \mu$ l of $0.9 \%$ saline solution containing $2 \%$ DMSO. ' Zileuton, $10 \mathrm{mg} / \mathrm{kg}$. ${ }^{D} \mathrm{MK} 886,0.5 \mathrm{mg} / \mathrm{kg}$; given i.p. 30 minutes prior to i.v. injection of $200 \mu \mathrm{g} / \mathrm{kg}$ PAF. ${ }^{\mathrm{E}} P=0.0301 \mathrm{vs}$. control (without testosterone); 2 sided Fisher's exact test. 


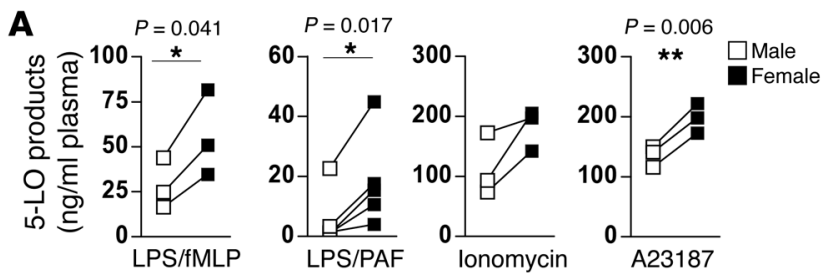

\section{B}
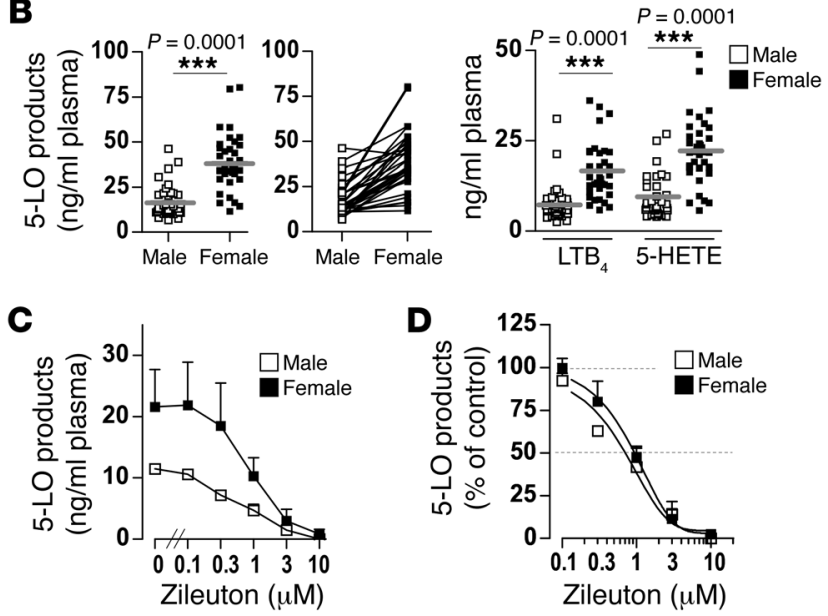

without significant effect in this respect. $5 \alpha$-DHT did not modify the efficiency of the direct 5-LO inhibitor zileuton in both male and female blood (Figure 3D). However, $5 \alpha$-DHT significantly impaired the effects of MK886 and licofelone in female, but not in male, blood, and a similar tendency was observed for Ssi (Figure 3D). In contrast, the efficiency of the inhibitors was not significantly affected by $17 \beta$-estradiol and progesterone.

Sex-related effects of LT biosynthesis inhibitors in neutrophils and monocytes. Sex-related potencies of LT biosynthesis inhibitors in blood might derive from diverse effects in LT-generating cells. Neutrophils and monocytes account for $80 \%$ and $20 \%$ of $5-\mathrm{LO}$ products in blood, respectively (34), which is in agreement with the relative number of neutrophils and monocytes in blood (neutrophils were $81.0 \% \pm 2.3 \%$ in males and $84.0 \% \pm 1.8 \%$ in females of the total number of neutrophils plus monocytes; $n=6$ ). While eosinophils are major sources for cysLTs in asthmatic airways (35), they are sparsely present in blood ( $1 \%-4 \%$ of leukocytes) and require laborious isolation where reversible androgen effects may vanish (11), making respective studies with isolated eosinophils difficult. After normalization on the sum of neutrophils and monocytes, the amount of 5-LO products was higher in LPS/fMLP-stimulated blood from females versus males (Supplemental Figure 3A). Accordingly, formation of 5-LO products in isolated neutrophils and monocytes from females stimulated by LPS/fMLP was higher compared with those in male cells, while the products of other LOs were either not different or even partially higher in males (e.g., 12and 15-HETE in monocytes; LC-MS/MS in Supplemental Figure 3). In intact cells, $\mathrm{LTB}_{4}$ was detected as the main 5-LO product and thus evaluated in subsequent inhibitor studies.

In female neutrophils, superior potencies of MK886 and licofelone were observed compared with those in males (Figure $4 \mathrm{~A}$ ), which were abolished upon preincubation at $37^{\circ} \mathrm{C}$ with $5 \alpha$-DHT (Figure 4B). The less pronounced sex bias under these
Figure 2. Sex-related differences in 5-LO product biosynthesis in human blood and effects of zileuton. (A) Formation of 5-LO products (i.e., LTB its trans isomers, and 5-HETE) in male and female whole blood stimulated with LPS $(1 \mu \mathrm{g} / \mathrm{ml} ; 30$ minutes) plus fMLP $(1 \mu \mathrm{M} ; 15$ minutes $)$ or plus PAF ( $1 \mu \mathrm{M} ; 15$ minutes), ionomycin (50 $\mu \mathrm{M} ; 15$ minutes), or A23187 (30 $\mu \mathrm{M} ; 10$ minutes) at $37^{\circ} \mathrm{C}$. Data are expressed as $\mathrm{ng} / \mathrm{ml}$ plasma, lines connect dots corresponding to the pair-wise male/female analyses at different experimental days; paired 2-tailed $t$ test. (B) 5-LO product formation in male and female whole blood stimulated with LPS/fMLP (DMSO, 0.2\%). Data are expressed as $\mathrm{ng} / \mathrm{ml}$ plasma, $n=35$; paired 2-tailed $t$ test. Data passed normality test. Left panel: all 5-LO products; bars indicate means. Middle panel: all 5-LO products; lines connect dots corresponding to the pair-wise male/female analyses at different experimental days. Right panel: data for LTB $_{4}$ and 5-HETE. (C and $\mathbf{D}$ ) Effects of zileuton on 5-LO product formation in male and female whole blood stimulated with LPS/fMLP. Data are expressed as $\mathrm{ng} / \mathrm{ml}$ plasma (C) or percentage of control (D); mean + SEM; $n=4$ male and $n=4$ female. ${ }^{*} P<0.05 ;{ }^{*} P<0.01 ;{ }^{* * *} P<0.001$.

conditions (compared with whole blood, Figure 3, A and B) may depend on the reversibility of the hormonal effects during and after cell isolation from blood (11). No significant sex- or $5 \alpha$-DHTrelated difference was observed for zileuton and Ssi (at 1 and 10 $\mu \mathrm{M}$, respectively, concentrations higher than the $\mathrm{IC}_{50}$; Figure 4A and Supplemental Figure 4). In monocytes, licofelone and Ssi were more active in females, and zileuton and MK886 were instead equally potent between the sexes (Figure 4C and Supplemental Figure 4). Preincubation of monocytes with $5 \alpha$-DHT partially reduced the effect of Ssi in female cells (Supplemental Figure 4). Notably, the mechanisms for sex-related differences in 5-LO product formation were cell type dependent: in neutrophils, agonist-induced 5-LO nuclear membrane association differed between male and female cells (11), while in monocytes, sex differences in 5-LO activity were instead related to variant PLD activities (12). Conclusively, some sex differences observed in whole blood seem to be mediated by neutrophils (MK886) and others by monocytes (Ssi) or both cell types (licofelone), and androgens are seemingly responsible for these differences.

5-LO/FLAP complex assembly is sex dependent and blocked by $5 \alpha-D H T$. A common feature of those LT synthesis inhibitors that were affected by the sex or $5 \alpha$-DHT is their ability to prevent 5 -LO/ FLAP interaction, either by blocking 5-LO nuclear translocation (i.e., licofelone and Ssi) $(32,33)$ or by direct binding to FLAP (i.e., MK886 and BAY-X 1005) (7). We thus hypothesized that a sex bias in 5-LO/ FLAP interaction, due to androgens, might underlie the different efficiencies of FLAP inhibitors and licofelone/Ssi. 5-LO/FLAP complex assembly at the nuclear membrane was studied using PLA that unravels in situ interactions of proteins that are in close proximity $(<40 \mathrm{~nm})(7,36)$. In resting human neutrophils and monocytes of both sexes, only sporadic 5-LO/FLAP signals were detectable (Figure 5A). Interestingly, in A23187-stimulated cells from females, substantial 5-LO/FLAP interaction signals were evident, but only 
A
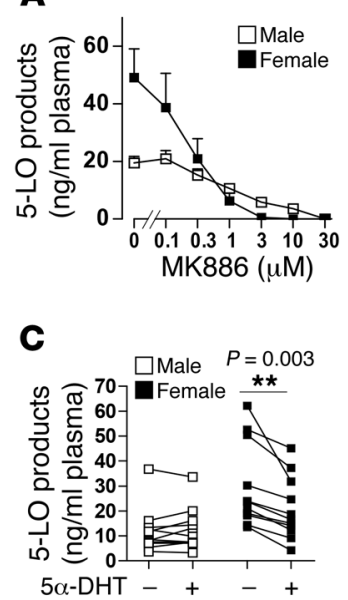
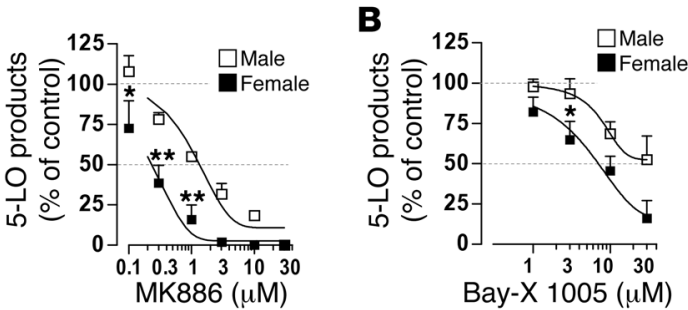
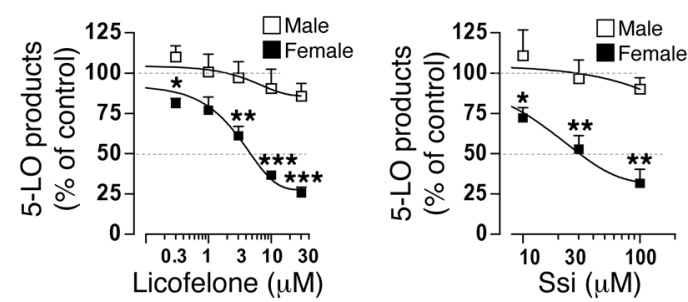
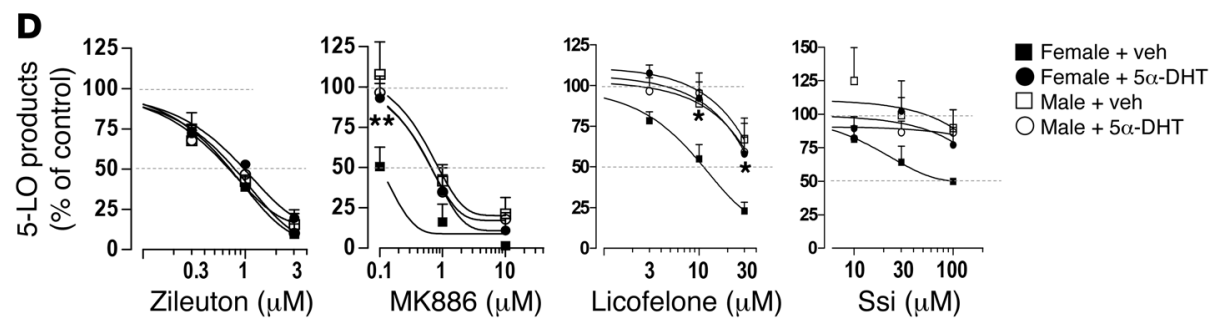

Figure 3. FLAP inhibitors and novel-type 5-LO inhibitors are more potent in female than in male blood. Effects of the FLAP inhibitors MK886 (A) and BAY-X 1005 and of the novel-type 5-LO inhibitors licofelone and Ssi (B) on 5-LO product formation in male and female blood stimulated at $37^{\circ} \mathrm{C}$ with LPS (1 $\mu \mathrm{g} / \mathrm{ml} ; 30$ minutes) and fMLP (1 $\mu \mathrm{M} ; 15$ minutes). Data are expressed as $\mathrm{ng} / \mathrm{ml}$ plasma (A, left panel) or as percentage of control (A, right panel; B), means $+\mathrm{SEM} ; n=4$. The amount of (B) 5-LO products in 100\% controls were as follows: BAY-X 1005: male, $9.9 \pm 1.0 \mathrm{ng} / \mathrm{ml}$; female, $37.8 \pm 5.4 \mathrm{ng} / \mathrm{ml}$; licofelone: male, $11.7 \pm 0.9 \mathrm{ng} / \mathrm{ml}$; female, $27.5 \pm 6.0 \mathrm{ng} / \mathrm{ml}$; Ssi: male, $18.2 \pm 4.5 \mathrm{ng} / \mathrm{ml}$; female, $39.2 \pm 10.1 \mathrm{ng} / \mathrm{ml}$. ${ }^{*} P<0.05 ;{ }^{* *} P<0.01 ;{ }^{* *} P<0.001 \mathrm{vs}$. corresponding male, ANOVA plus Bonferroni. (C) 5 -LO product formation in male and female whole blood stimulated at $37^{\circ} \mathrm{C}$ with LPS $(1 \mu \mathrm{g} / \mathrm{ml} ; 30 \mathrm{minutes})$ and fMLP $(1 \mu \mathrm{M}$; 15 minutes) after preincubation for 10 minutes with vehicle $(0.05 \% \mathrm{EtOH})$ or $5 \alpha-\mathrm{DHT}(30 \mathrm{nM}) ; n=11$; paired $t$ test. (D) Effects of zileuton, MK886, licofelone, and SSi on 5-LO product formation in female and male blood stimulated with LPS/fMLP after preincubation for 10 minutes with vehicle (0.05\% $\mathrm{EtOH})$ or $5 \alpha$-DHT (30 nM). Data are expressed as percentage of control, mean + SEM; $n=4$. 5-LO products in 100\% controls were as follows: zileuton: male, $7.3 \pm 0.2 \mathrm{ng} / \mathrm{ml}$ (veh) and $7.3 \pm 0.1 \mathrm{ng} / \mathrm{ml}(5 \alpha-\mathrm{DHT}) ;$ female, $25.5 \pm 4.6 \mathrm{ng} / \mathrm{ml}$ (veh) and $18.5 \pm 6 \mathrm{ng} / \mathrm{ml}(5 \alpha-\mathrm{DHT}) ; \mathrm{MK} 886: \mathrm{male}, 9.7 \pm 1.4 \mathrm{ng} / \mathrm{ml}$ (veh) and $10.1 \pm 1.6 \mathrm{ng} / \mathrm{ml}(5 \alpha-\mathrm{DHT})$; female, $42.8 \pm 14.0 \mathrm{ng} / \mathrm{ml}$ (veh) and $27.1 \pm 12.0 \mathrm{ng} / \mathrm{ml}(5 \alpha-\mathrm{DHT}) ;$ licofelone: male, $19.4 \pm 9.0 \mathrm{ng} / \mathrm{ml}$ (veh) and $20.4 \pm 7.5 \mathrm{ng} / \mathrm{ml}$ $(5 \alpha-\mathrm{DHT})$; female, $30.8 \pm 9.9 \mathrm{ng} / \mathrm{ml}$ (veh) and $22.6 \pm 7.3 \mathrm{ng} / \mathrm{ml}(5 \alpha-\mathrm{DHT}) ;$ Ssi: male, $9.6 \pm 3.0 \mathrm{ng} / \mathrm{ml}$ (veh) and $11.3 \pm 4.0 \mathrm{ng} / \mathrm{ml}(5 \alpha-\mathrm{DHT})$; female, $19.1 \pm 2.7$ $\mathrm{ng} / \mathrm{ml}$ (veh) and $14.3 \pm 2.8 \mathrm{ng} / \mathrm{ml}(5 \alpha-\mathrm{DHT}) .{ }^{*} P<0.05 ;{ }^{*} P<0.01$ for female plus $5 \alpha-\mathrm{DHT}$ vs. female plus vehicle, ANOVA plus Bonferroni.

very few appeared in stimulated male cells (Figure 5A). Accordingly, pretreatment of female neutrophils and monocytes with 10 nM $5 \alpha$-DHT for only 10 minutes prevented 5-LO/FLAP complex formation (Figure $5 \mathrm{~B}$ ), which is actually a typical feature of FLAP inhibitors, such as MK886 (100 nM, Figure 5B) and BAY-X 1005 (7). Note that $5 \alpha$-DHT exposure for only 3 minutes suffices to suppress 5 -LO product formation in monocytes without marked changes for prolonged preincubation periods (Supplemental Figure 5). Moreover, to correlate the androgen-related sex differences of LT levels in mouse peritonitis (see Figure 1, C and D) to 5-LO/FLAP interactions, we studied 5-LO/FLAP complex assembly in resident PMs isolated from male and female mice. Only in female PMs, 5-LO/ FLAP signals were observed after A23187 challenge, and preincubation with $10 \mathrm{nM} 5 \alpha$-DHT (for 10 minutes) prevented 5-LO/FLAP complex formation (Figure 5C). Together, these data imply that the assembly of 5-LO/FLAP complexes upon cell activation by A23187 occurs preferentially in female cells and that it is impeded by androgens. The observation that 5-LO/FLAP complex assembly is hardly operative in male or $5 \alpha$-DHT-treated females cells may explain why inhibitors preventing the 5-LO/FLAP interaction are less effective in males or in females under testosterone treatment.

\section{Discussion}

Here we report on a sex bias in the efficiency of clinically relevant inhibitors of LT biosynthesis, i.e., various FLAP inhibitors and novel-type 5-LO inhibitors that are superior in females. We provide evidence that androgens cause these sex differences in vivo and in vitro, and we show that androgens impede the agonist-induced, tight assembly of the 5-LO/FLAP complex at the nuclear membrane of human and murine leukocytes. Conclusively, females should benefit more from anti-LT therapy than males. Based on the current active development of LT-modifying agents as therapeutics in respiratory and cardiovascular diseases, our data prompt consideration of sex differences in biomedical studies related to anti-LTs in order to improve their efficacy and to optimize dosage for both men and women.

Sex differences in LT biosynthesis in vivo are clearly supported by the elevated $\mathrm{LTB}_{4}$ levels in inflammatory exudates from female versus male animals in 2 different, well-established models of LT-driven acute inflammation: carrageenan-induced pleurisy in rats (37) and zymosan-induced peritonitis in mice (38). Of interest, short-term application of $5 \alpha$-DHT reduced $\mathrm{LTB}_{4}$ levels during peritonitis in female, but not male, mice. These data support our previous findings on sex disparities related to androgens in murine zymosan-induced peritonitis (13). Androgen-mediated sex differences were recently shown in a multiple sclerosis mouse model (39), where LT signaling contributes to pathology (40). Although the relevance of these findings for humans needs to be confirmed in clinical studies, they may imply a greater contribution of LTs in the pathology of females than of males, which is most obvious for asthma, which clearly dominates in females (9). Interestingly, the cysLT antagonist montelukast significantly reduced asthma morbidity in girls and prepubertal boys, but not in boys reaching puberty, in a placebo-controlled study (41). Possibly, in pubertal 

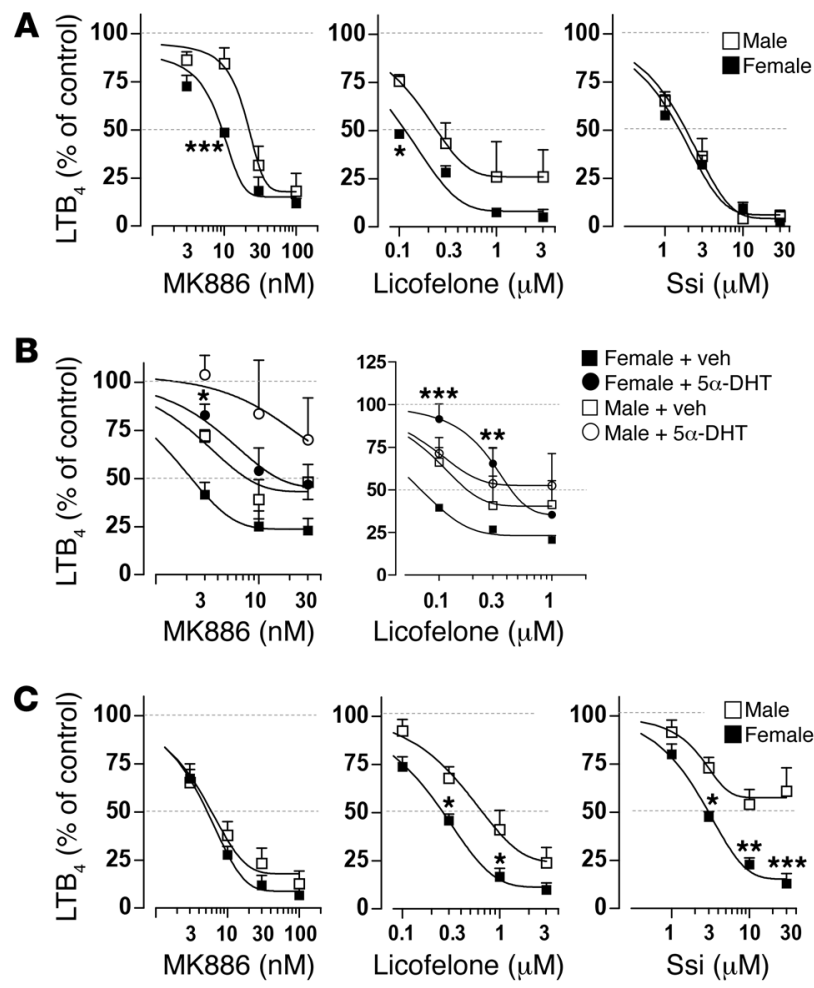

boys with elevated androgen levels, cysLT formation is lower, with inferior contribution to the asthmatic response; thus, the LT modifier is less effective.

In the pleurisy and peritonitis models, MK886 reduced $\mathrm{LTB}_{4}$ levels in inflamed exudates more efficiently in female versus male animals, although sex differences in pharmacokinetics of MK886 in mice were not apparent. Also, the direct 5-LO inhibitor zileuton showed a partial sex bias, indicating that additional mechanisms such as AA supply by CPLA, its binding to FLAP, and transfer to 5-LO or cell uptake, export, and metabolism of the drugs may be relevant for sex differences in vivo besides 5-LO/FLAP interactions. Furthermore, both MK886 and zileuton were superior in female versus male mice treated with PAF, but after administration of testosterone, only the protective effect of MK886 was abolished. These data essentially confirm androgen-related discrepancies in the efficiency of MK886. The mortality rate of male and female mice upon PAF was similar and not affected by testosterone, suggesting that factors other than LTs mediate the lethal effect of PAF in male animals. Interestingly, genetic modulation of LT biology (e.g., BLT1 knockout) caused sex differences in response to PAF (15), confirming a more prominent role of LTs in females and a possible involvement of other factors in males (42). High efficacy of FLAP inhibitors in female mice in different in vivo models were reported by others. Thus, MK886 and BAY-X 1005 attenuated atherosclerosis in female Apoe/Ldlr double-knockout mice (42-44) and the FLAP inhibitors AM103 and AM803 efficiently reduced lethality in PAF-induced shock in female mice $(45,46)$. However, a direct comparison with male animals was not performed in those studies.

In agreement with previous data (11), challenge of human whole blood from females caused higher formation of various 5-LO-derived products (including the $\mathrm{LTB}_{4}$ metabolite $20-\mathrm{OH}$ $\mathrm{LTB}_{4}$ ) as compared with males, and $5 \alpha$-DHT reduced all these
Figure 4. Effect of LT synthesis inhibitors in male and female neutrophils and monocytes. Effects of MK886, licofelone, or Ssi on $\mathrm{LTB}_{4}$ formation in male and female (A and $\mathbf{B})$ neutrophils stimulated at $37^{\circ} \mathrm{C}$ with LPS $(1 \mu \mathrm{g} /$ $\mathrm{ml} ; 30$ minutes) or Ada ( $0.3 \mathrm{U} / \mathrm{ml} ; 20$ minutes) plus fMLP ( $1 \mu \mathrm{M} ; 5$ minutes) and (C) monocytes stimulated at $37^{\circ} \mathrm{C}$ with LPS $(1 \mu \mathrm{g} / \mathrm{ml} ; 15$ minutes) plus fMLP $(1 \mu \mathrm{M} ; 10$ minutes). In B, cells were preincubated for 10 minutes with vehicle $(0.05 \% \mathrm{EtOH})$ or $5 \alpha-\mathrm{DHT}(10 \mathrm{nM})$. Data are expressed as percentage of control, mean + SEM; $n=3 .{ }^{*} P<0.05 ;{ }^{* *} P<0.01 ;{ }^{* *} P<0.001$ vs. corresponding male (A and $\mathbf{C}$ ). ${ }^{*} P<0.05$; ${ }^{* *} P<0.01$; ${ }^{* *} P<0.001$ for female plus $5 \alpha$-DHT vs. female plus vehicle, ANOVA plus Bonferroni (B). The amount of $\mathrm{LTB}_{4}$ in $100 \%$ controls was as follows: (A) male, $1.0 \pm 0.3 \mathrm{ng}$ per $10^{7}$ cells; female, $2.4 \pm 1.0 \mathrm{ng}$ per $10^{7}$ cells; (B) male, $1.4 \pm 0.1 \mathrm{ng}$ per $10^{7}$ cells (veh) and $1.2 \pm 0.2 \mathrm{ng}$ per $10^{7}$ cells $(5 \alpha-\mathrm{DHT})$; female, $3.3 \pm 0.5 \mathrm{ng}$ per $10^{7}$ cells (veh) and $2.1 \pm 0.2 \mathrm{ng}$ per $10^{7}$ cells ( $5 \alpha-\mathrm{DHT}$ ); (C) male, $4.8 \pm 1.8 \mathrm{ng}$ per $10^{7}$ cells; female, $11.9 \pm 2.7 \mathrm{ng}$ per $10^{7}$ cells.

5-LO products to a similar degree in female blood. We demonstrate here that, besides the capacity to generate LTs, the potency of certain pharmacological inhibitors is strongly influenced by the sex. Our previous studies showed that expression of 5-LO, $\mathrm{CPLA}_{2}$, and FLAP as well as the catalytic activity of 5-LO in cell-free assays is not different between the sexes $(11,12)$. Accordingly, compounds acting as direct inhibitors of 5-LO catalytic activity (iron ligand type, redox type, and nonredox type) and a direct $\mathrm{CPLA}_{2}$ inhibitor suppressed 5-LO product biosynthesis in human blood of females and males with comparable potencies. In contrast, compounds affecting 5-LO product formation primarily by interfering with its cellular regulation, such as the FLAP inhibitors and the novel-type 5-LO inhibitors licofelone and Ssi, which all prevent the assembly of the LT-biosynthetic 5-LO/FLAP complex, were markedly more potent in female versus male blood.

Previous data suggested that the sex bias in LT formation is related to discrepancies in the subcellular localization of 5-LO. Thus, sex differences in the intracellular trafficking of 5-LO in human neutrophils (11) and murine PMs (13) may cause a bias in 5-LO/FLAP complex assembly at the nuclear membrane. Using PLA that allows detection of in situ 5-LO/FLAP interaction in leukocytes (7), we found marked assembly of tight 5-LO/FLAP complexes ( $<40 \mathrm{~nm}$ distance; ref. 36) in A23187-challenged human neutrophils and monocytes as well as murine PMs from females, but not in male counterparts. Accordingly, pretreatment of female cells with $5 \alpha$-DHT impeded 5-LO/FLAP interaction signals, effects that are typical for FLAP inhibitors (7). We conclude that the lower capacity of males to produce 5 - $\mathrm{LO}$ products is due to androgens that can impede productive 5-LO/FLAP interactions and thus may hinder AA transfer via FLAP to 5-LO. Note that cPLA ${ }_{2}$ translocation and AA release were equal for male and female neutrophils, and exogenous AA supply abolished sex differences in 5-LO product synthesis in neutrophils (11).

Pharmacological and genetic approaches in vitro and in vivo revealed the strong requirement of FLAP for cellular LT biosynthesis $(4,27,47,48)$. FLAP inhibitors reduce LT biosynthesis by preventing the interaction between FLAP and 5-LO at the nuclear membrane (7), thereby blocking AA transfer from FLAP to 5-LO (5). Therefore, $5 \alpha$-DHT and FLAP inhibitors share the ability to modulate the LT-biosynthetic 5-LO/FLAP interaction in neutrophils and monocytes, and both impair 5-LO product biosynthesis. Besides FLAP inhibitors, the novel-type LO inhibitors licofelone 
A
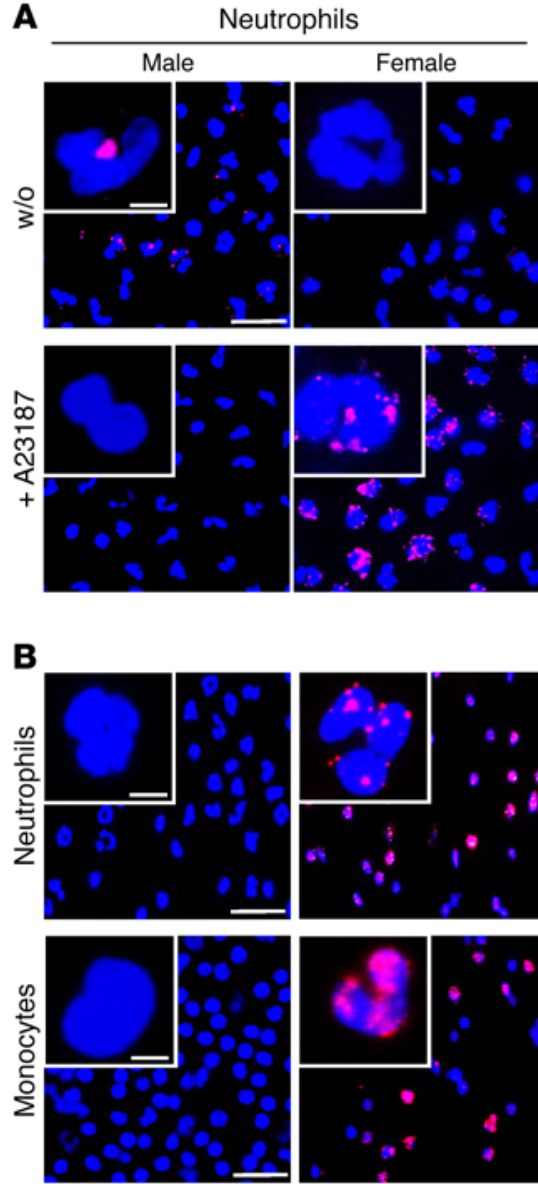

A23187

$5 \alpha-\mathrm{DHT}$

MK886

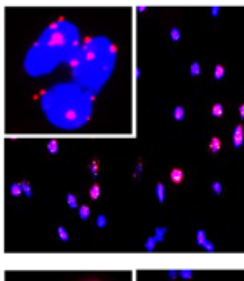

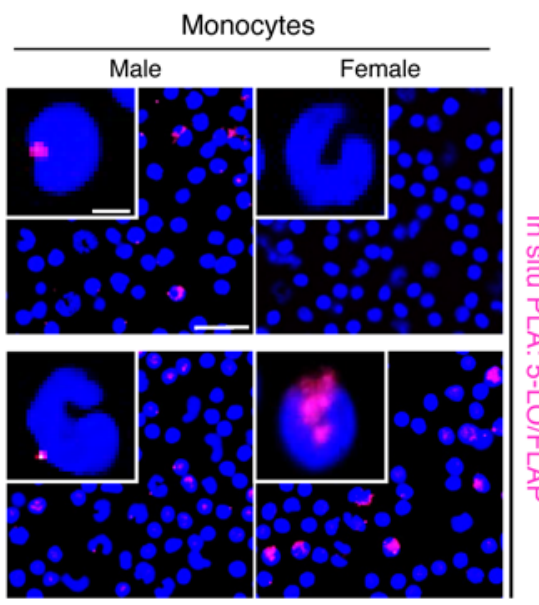
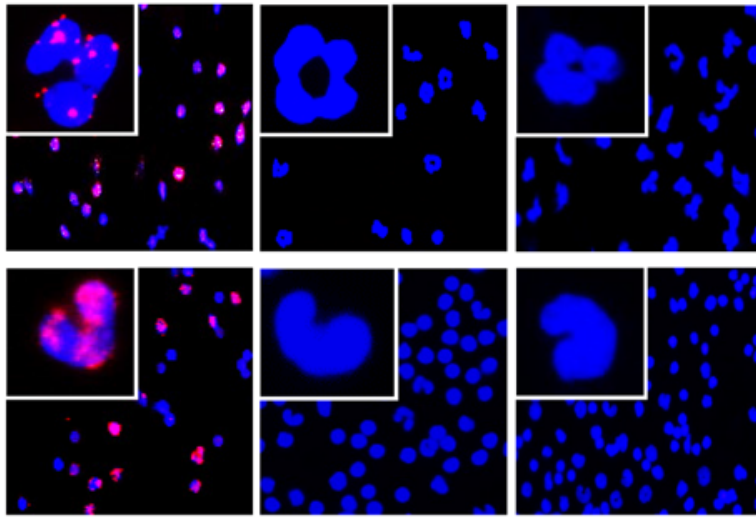

$+$

$+$
C

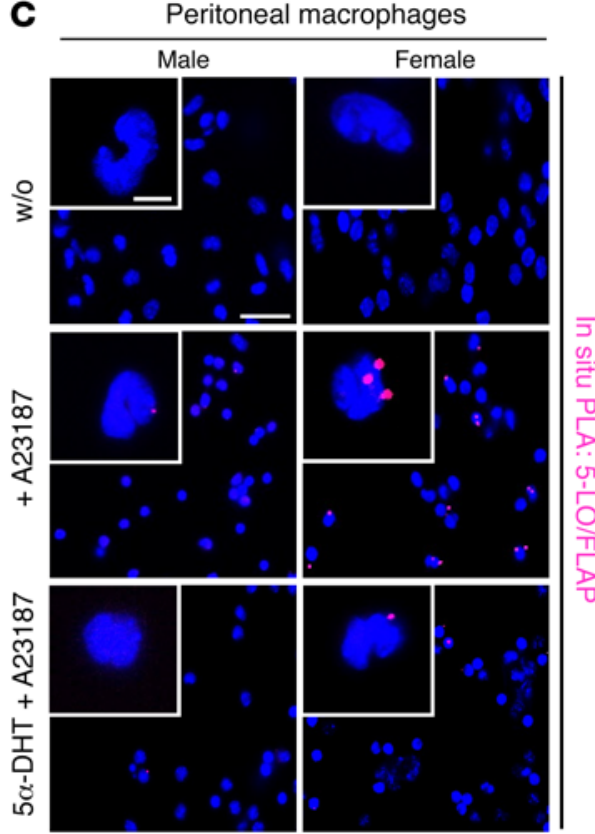

Figure 5. 5-LO/FLAP complex assembly is sex dependent and blocked by $\mathbf{5} \alpha$-DHT. (A) Human male and female neutrophils or monocytes were stimulated at $37^{\circ} \mathrm{C}$ with $2.5 \mu \mathrm{M} \mathrm{A} 23187$ or left untreated $(\mathrm{w} / \mathrm{o})$ for 15 minutes. (B) Female neutrophils or monocytes were preincubated at RT for 10 minutes with $10 \mathrm{nM}$ $5 \alpha$-DHT, $100 \mathrm{nM}$ MK886, or vehicle (0.1\% DMSO) and then stimulated with $2.5 \mu \mathrm{M} \mathrm{A23187} \mathrm{or} \mathrm{left} \mathrm{untreated} \mathrm{for} 20$ minutes. (C) PMs from male and female mice were preincubated at $37^{\circ} \mathrm{C}$ for 10 minutes with $10 \mathrm{nM} 5 \alpha$-DHT or vehicle ( $0.1 \%$ DMSO) and then stimulated with $2.5 \mu \mathrm{M}$ A23187 or left untreated for 20 minutes. Then, in situ PLA, using proximity probes against mouse anti-5-LO and rabbit anti-FLAP, was performed. DAPI (blue) was used to stain the nucleus, and in situ PLA signals (magenta dots) visualized 5-LO/FLAP interaction. Scale bars: $5 \mu \mathrm{m}$ (insets); $25 \mu \mathrm{m}$ (overview). Results are representative of approximately 100 individual cells of $n=3$ independent experiments.

and Ssi also exhibited different potencies in male and female blood. In contrast to other typical direct 5-LO inhibitors, licofelone and Ssi blocked 5-LO nuclear translocation, were more potent in intact cells than for isolated 5-LO, and, at least for licofelone, FLAP has been identified as a pharmacologically relevant target $(32,33)$. Together, the agonist-induced assembly of the tight LTbiosynthetic 5-LO/FLAP complex occurs primarily in female cells, but hardly in male cells (impeded by androgens), which explains why LT synthesis inhibitors that act by preventing the 5-LO/FLAP interaction are more effective in females. However, FLAP inhibitors and licofelone/Ssi still suppressed 5-LO product formation at high concentrations in male blood and neutrophils, suggesting that FLAP-mediated AA transfer to 5-LO is operative in both sexes. Possibly, in male cells (or in the presence of androgens), 5-LO and FLAP are in more distant proximity than in female cells $(>40$ $\mathrm{nm}$ ) and thus not detectable by PLA, with less efficient AA transfer capacity compared with that of tight 5-LO/FLAP complexes.
Sex-related differences in the efficiency of 5-LO inhibitors or FLAP inhibitors have not, to our knowledge, been reported before. Most studies were conducted using mainly (or only) one sex, or the sex was not considered (or reported) in the analysis of the results. In clinical trials, MK866 was evaluated in 8 atopic asthmatic men, leading to moderate LT inhibition as compared with the excellent in vitro activity (49). Its clinical investigation was discontinued. BAY-X 1005 significantly attenuated early and late allergen-induced bronchoconstriction in 10 atopic men with a history of asthma and reduced urinary $\mathrm{LTE}_{4}$ excretion (50), though there was no direct relation between drug plasma concentration and degree of inhibition. Moreover, BAY-X 1005 hardly lowered $\mathrm{LTB}_{4}$ in the sputum of patients with chronic obstructive pulmonary disease (male sex: 7 of 8 total; ref. 51). Human genetic studies have indicated stronger associations in males than in females between specific FLAP haplotypes and risk for myocardial infarction and stroke in populations in Ice- 
land and the United Kingdom (52, 53), which supported the evaluation of BAY-X 1005 effects on biomarkers of myocardial infarction risk. However, only a $26 \%$ reduction of $\mathrm{LTB}_{4}$ synthesis in human whole blood and a paradoxical $21 \%$ increase in urinary $\mathrm{LTE}_{4}$ levels were observed (where $75 \%$ were males, treatment and placebo; ref. 54). Note that in trials analyzing the effect of zileuton, sexes were equally represented, but sex-related differences were not mentioned $(55,56)$.

In summary, in vitro and animal in vivo evidence clearly indicate the existence of sex differences in the LT pathway. Our findings show that this testosterone-mediated sex bias affects the efficiency of clinically relevant LT biosynthesis inhibitors, strongly suggesting that therapy with LT modifiers should be evaluated with respect to sex.

\section{Methods}

Materials, determination of LO products by LC-MS/MS, and details on animal experiments can be found in the Supplemental Methods.

Animal studies. Male and female CD-1 mice (25-30 g) and male and female Wistar Han rats (200-240 g) obtained from Harlan were housed at the Department of Pharmacy (University of Naples Federico II) in a controlled environment $\left(21 \pm 2^{\circ} \mathrm{C}\right)$ and provided with standard rodent chow and water. Animals were allowed to acclimate for 4 days prior to experiments and were subjected to a 12-hour light/12-hour dark schedule. Experiments were conducted during the light phase.

For analysis by PLA, resident murine PMs were obtained by lavage of the peritoneal cavity of female and male mice with $7 \mathrm{ml}$ of cold DMEM with heparin $(5 \mathrm{U} / \mathrm{ml})$. PMs were then centrifuged at $500 \mathrm{~g}$ and $4^{\circ} \mathrm{C}$ for 5 minutes and resuspended at $1.5 \times 10^{6}$ cells $/ \mathrm{ml}$ in DMEM containing $5 \%$ of charcoal-stripped fetal calf serum.

For carrageenan-induced pleurisy in rats, zileuton, MK886, or vehicle ( $1.5 \mathrm{ml}$ of $0.9 \%$ saline solution containing $4 \% \mathrm{DMSO}$ ) was given i.p. at the indicated doses, 30 minutes before $\lambda$-carrageenan type IV $1 \%$ (w/v; $0.2 \mathrm{ml}$ ), which was injected into the thoracic cavity. The animals were killed by inhalation of $\mathrm{CO}_{2}$ at the indicated time point, the thoracic exudates were collected, and the amounts of $\mathrm{LTB}_{4}$ were assayed by an enzyme immunoassay kit (Cayman Chemical) according to the manufacturer's instructions. The results are expressed as ng per rat. More details can be found in the Supplemental Methods.

For the zymosan-induced peritonitis, mice ( $n=5$ per experimental group) received MK886 ( $1 \mathrm{mg} / \mathrm{kg}), 5 \alpha-\mathrm{DHT}(0.5 \mathrm{mg} / \mathrm{kg})$, or vehicle (0.5 $\mathrm{ml}$ of $0.9 \%$ saline solution containing $2 \%$ DMSO) i.p., $30 \mathrm{~min}-$ utes prior to zymosan, as previously described (38). Zymosan (SigmaAldrich) was prepared as a final suspension $(2 \mathrm{mg} / \mathrm{ml})$ in $0.9 \%(\mathrm{w} / \mathrm{v})$ saline and injected i.p. $(0.5 \mathrm{ml})$ after sonication. Mice were killed by inhalation of $\mathrm{CO}_{2}$ after 15 minutes, followed by a peritoneal lavage with $3 \mathrm{ml}$ of cold PBS. After 60 seconds of gentle manual massage, 2 $\mathrm{ml}$ of exudates were collected and centrifuged $(18,000 \mathrm{~g}, 5$ minutes, $\left.4^{\circ} \mathrm{C}\right)$; $\mathrm{LTB}_{4}$ levels in the supernatant were assessed by LC-MS/MS analyses (see Supplemental Methods).

For the PAF-induced shock, mice were challenged with $200 \mu \mathrm{g} /$ $\mathrm{kg}$ PAF in a volume of $200 \mu \mathrm{l}$ via a tail vein injection 30 minutes after an i.p. injection of either vehicle ( $0.5 \mathrm{ml} 2 \% \mathrm{DMSO})$ or compounds at the indicated dose. In experiments where the effect of testosterone was evaluated, mice were treated daily by subcutaneous injection of sesame oil (vehicle, $100 \mu \mathrm{l}$ ) or testosterone propionate $(3 \mathrm{mg} / \mathrm{kg}$ ) for 10 days prior to PAF injection.
For analysis of plasma levels of MK886, mice ( $n=3$ male and $n=3$ female) received $1 \mathrm{mg} / \mathrm{kg}$ i.p. injection in a volume of $500 \mu \mathrm{l}$ of $0.9 \%$ saline. After selected time points, mice were sacrificed $\left(\mathrm{CO}_{2}\right.$ atmosphere) and blood (approximately $0.7-0.9 \mathrm{ml}$ ) was collected by intracardiac puncture using citrate as anticoagulant. Then plasma was obtained by centrifugation at $800 \mathrm{~g}$ at $4^{\circ} \mathrm{C}$ for 10 minutes and immediately frozen at $-80^{\circ} \mathrm{C}$. MK886 was extracted from samples by solid phase extraction and analyzed by LC-MS/MS, as reported in Supplemental Methods.

Preparation of human whole blood and prompt isolation of neutrophils and monocytes. Preparation of human whole blood and isolation of neutrophils and monocytes from leukocyte concentrates were performed as described $(11,12)$. Venous blood was collected in heparinized tubes (16 IU heparin/ml blood) from fasted (12 hours) adult (18-65 years) male and female registered, healthy volunteers at the Institute of Transfusion Medicine, University Hospital Jena. These subjects, who donated blood every 8 to 12 weeks, had no apparent infections, inflammatory conditions, or current allergic reactions (according to prior physical inspection by a clinician) and had not taken sex hormones, antibiotics, or antiinflammatory drugs for at least 10 days prior to blood collection. Where indicated, a blood count was performed by an automated hematology analyzer (Sysmex KX-21N, Sysmex Deutschland $\mathrm{GmbH})$. Leukocytes were immediately concentrated by centrifugation $\left(4,000 \mathrm{~g} / 20 \mathrm{~min} / 20^{\circ} \mathrm{C}\right)$ of the freshly withdrawn blood. Neutrophils were promptly isolated by dextran sedimentation, centrifuged on lymphocyte separation medium (LSM 1077, PAA Laboratories), and subjected to hypotonic lysis of erythrocytes. Monocytes were separated from peripheral blood mononuclear cells (PBMCs) by adherence to culture flasks or to glass coverslips at $37^{\circ} \mathrm{C}$ for $90 \mathrm{~min}$ utes. For determination of 5-LO products, neutrophils and monocytes were resuspended in PBS plus glucose (0.1\%, PG buffer) to a final cell density of $5 \times 10^{6}$ and $2 \times 10^{6}$ cells $/ \mathrm{ml}$, respectively.

Determination of 5-LO product synthesis. Aliquots of human blood $(2 \mathrm{ml})$ were preincubated with $1 \mu \mathrm{g} / \mathrm{ml} \mathrm{LPS}$ for 30 minutes at $37^{\circ} \mathrm{C}$, and formation of 5-LO products was started by the addition of fMLP $(1 \mu \mathrm{M})$ or PAF $(100 \mathrm{nM})$ for 15 minutes at $37^{\circ} \mathrm{C}$. Blood was stimulated within 30 minutes after sampling unless stated otherwise. Test compounds or vehicle (0.1\% DMSO) was added 10 minutes before fMLP. Since priming with LPS enhances AA release by stimulating $\mathrm{CPLA}_{2}$, the $\mathrm{CPLA}_{2}$ inhibitor pyrrolidine-1 (RSC-3388) was added 10 minutes before LPS. All vehicle controls were summarized $(n=35)$. $5 \alpha$-DHT $(30 \mathrm{nM})$ was added 10 minutes prior to LPS. After stimulation, samples were placed on ice and centrifuged $\left(600 \mathrm{~g}, 10\right.$ minutes, $\left.4^{\circ} \mathrm{C}\right)$; aliquots of the resulting plasma $(500 \mu \mathrm{l})$ were then mixed with $2 \mathrm{ml}$ of methanol, and 200 ng prostaglandin $\mathrm{B}_{1}\left(\mathrm{PGB}_{1}\right)$ was added as an internal standard. The samples were placed at $-20^{\circ} \mathrm{C}$ for 2 hours and centrifuged again $(600 \mathrm{~g}$, 15 minutes, $4^{\circ} \mathrm{C}$ ). The supernatants were collected and diluted with 2.5 $\mathrm{ml} \mathrm{PBS}$ and $75 \mu \mathrm{l} 1 \mathrm{~N} \mathrm{HCl}$; formed 5-LO products were extracted and analyzed by HPLC as described (11). For HPLC analysis, 5-LO product formation is expressed as ng of 5-LO products per ml of plasma. The 5-LO products include $\mathrm{LTB}_{4}$, its all-trans isomers, and 5-H(P)ETE, unless stated otherwise. Where indicated, LC-MS/MS analyses were performed (see Supplemental Methods).

For assays of intact cells, neutrophils $\left(5 \times 10^{6}\right.$ or $\left.2 \times 10^{7} / \mathrm{ml}\right)$ or monocytes $\left(5 \times 10^{6}\right.$ or $\left.1 \times 10^{7} / \mathrm{ml}\right)$ were resuspended in $1 \mathrm{ml} \mathrm{PG}$ buffer plus $1 \mathrm{mM} \mathrm{CaCl}$ (PGC buffer). Neutrophils were primed at $37^{\circ} \mathrm{C}$ with $1 \mu \mathrm{g} / \mathrm{ml}$ LPS plus $0.3 \mathrm{U} / \mathrm{ml}$ adenosine deaminase (Ada) for $30 \mathrm{~min}$ utes and stimulated with $1 \mu \mathrm{M}$ fMLP for 5 minutes. Monocytes were 
primed at $37^{\circ} \mathrm{C}$ with $1 \mu \mathrm{g} / \mathrm{ml}$ LPS for 15 minutes and stimulated with $1 \mu \mathrm{M}$ fMLP for 10 minutes. The reactions were stopped with $1 \mathrm{ml}$ of methanol and $30 \mu \mathrm{l}$ of $1 \mathrm{~N} \mathrm{HCl} ; 200 \mathrm{ng} \mathrm{PGB}$ and $500 \mu \mathrm{l}$ of PBS were added. Test compounds or vehicle (0.1\% DMSO) were added $10 \mathrm{~min}$ utes before fMLP. Formed 5-LO products were extracted and analyzed as described for whole blood.

Analysis of 5-LO/FLAP interaction by in situ proximity ligation assay. To detect in situ interaction of 5-LO with FLAP in neutrophils, monocytes, or PMs, an in situ proximity ligation assay (PLA) (36) was performed as described before (7). Neutrophils were preincubated with $5 \alpha$-DHT, MK-886, or vehicle for 10 minutes at room temperature (RT) in PGC buffer and centrifuged onto poly-D-lysine-coated glass coverslips (10 $g$ for 2 seconds). For monocyte analysis, PBMCs were seeded onto glass coverslips and cultured for 1 hour prior to preincubation with $5 \alpha$-DHT, MK886, or vehicle for 10 minutes at RT. For analysis of murine PMs, cells $\left(1.5 \times 10^{6} / \mathrm{ml}\right.$ DMEM) were seeded onto glass coverslips and kept at $37^{\circ} \mathrm{C}$ for 2 hours in order to adhere to the coverslips.

Neutrophils, monocytes, or PMs were preincubated with $10 \mathrm{nM}$ $5 \alpha$-DHT, $100 \mathrm{nM} \mathrm{MK886}$, or vehicle (0.1\% DMSO) for 10 minutes at $37^{\circ} \mathrm{C}$ prior to stimulation with $\mathrm{A} 23187(2.5 \mu \mathrm{M})$ for 20 minutes at $37^{\circ} \mathrm{C}$ and stopped by fixation with $4 \%$ paraformaldehyde. Acetone ( 3 minutes, $4^{\circ} \mathrm{C}$ ) was used to permeabilize monocytes and PMs, and $0.1 \%$ saponine was used for neutrophil permeabilization prior to blocking with nonimmune goat serum. Samples were incubated with mouse monoclonal anti-5-LO antibody (1:100, gift of Dieter Steinhilber, Goethe University Frankfurt, Frankfurt, Germany) and rabbit polyclonal anti-FLAP antibody $(5 \mu \mathrm{g} / \mathrm{ml}$, Abcam, catalog ab85227) at $4^{\circ} \mathrm{C}$ overnight. The cells were then incubated with species-specific secondary antibodies conjugated with oligonucleotides (PLA probe anti-mouse MINUS and anti-rabbit PLUS) for 1 hour at $37^{\circ} \mathrm{C}$. After addition of 2 other circle-forming DNA oligonucleotides and a ligase (30 minutes at $37^{\circ} \mathrm{C}$ ), the newly generated DNA circle was amplified by rolling circle amplification for 100 minutes at $37^{\circ} \mathrm{C}$ and visualized by hybridization with fluorescently labeled oligonucleotides. Cells were fixed on glass slides, and nuclear DNA was stained with ProLong Diamond Antifade Mountant with DAPI (Invitrogen). The PLA interaction signals (fluorescent spots, magenta) were analyzed by fluorescence microscopy using a Zeiss Axiovert 200M microscope and a Plan Neofluar $\times 40 / 1.30$ oil (DIC III) objective (Carl Zeiss).

Statistics. Results are expressed as mean \pm SEM of $n$ observations, where $n$ represents the number of experiments performed on different days or the number of animals, as indicated. Analyses of data were conducted using GraphPad Prism software. The $\mathrm{IC}_{50}$ values were determined by linear interpolation and validated with the GraphPad Instat program. Data fit was obtained using the sigmoidal doseresponse equation (variable slope) or the linear regression (GraphPad Prism software). Statistical evaluation of the data was performed by repeated-measures 1-way ANOVA followed by Bonferroni's post-hoc test for selected pairs. Where appropriate, 2-tailed Student's $t$ test was applied. For contingency tables, Fisher's exact test was used. Tests were conducted using a 2 -sided $\alpha$ level of 0.05 . For evaluation of normal distribution of data, the Kolmogorov-Smirnov test was used. Significance was defined as $P<0.05$.

Study approval. Animal studies were approved by the local ethical committee of the University of Naples Federico II. Animal care was in compliance with Italian regulations on the protection of animals used for experimental and other scientific purpose (Ministerial Decree 116/92) as well as European Economic Community regulations (Official Journal of E.C. L 358/1 12/18/1986). The protocols for experiments with human neutrophils and monocytes were approved by the ethical commission of Friedrich-Schiller-University Jena. All methods were performed in accordance with relevant guidelines and regulations. All human subjects gave informed consent.

\section{Author contributions}

SP designed, performed, and analyzed animal studies and studies with human whole blood and leukocytes and wrote parts of the manuscript. CP designed, performed, and analyzed experiments with human whole blood and leukocytes and wrote parts of the manuscript. FD designed, performed, and analyzed animal studies. AR designed, performed, and analyzed animal studies. JG performed PLAs. FT designed, performed, and analyzed animal studies. AMS performed and analyzed experiments with human whole blood. HP performed MK886 analysis in murine plasma by LC-MS/MS. CW prepared human blood and leukocytes. SR prepared human blood and leukocytes. HN prepared human blood and leukocytes. SL designed inhibitor studies and analyzed data. TJM designed inhibitor studies and analyzed data. OR designed experiments and analyzed data. BS designed experiments and analyzed data. AK designed, performed, and analyzed experiments with leukocytes. LS designed and analyzed animal studies and wrote parts of the manuscript. OW designed and analyzed experiments and wrote the manuscript.

\section{Acknowledgments}

This work was supported by the Deutsche Forschungsgemeinschaft, SFB 1127 (ChemBioSys) and the State of Thuringa ProExcellence Initiative 2 (RegenerAging). CP received a Carl-Zeiss stipend. We thank Bianca Jazzar for expert technical assistance.

Address correspondence to: Oliver Werz, Department of Pharmaceutical/Medicinal Chemistry, Institute of Pharmacy, FriedrichSchiller-University Jena, Philosophenweg 14, 07743 Jena, Germany. Phone: 49.0.3641.949801; Email: oliver.werz@uni-jena.de.
1. Peters-Golden M, Henderson WR. Leukotrienes. N Engl JMed. 2007;357(18):1841-1854.

2. Rådmark O, Werz O, Steinhilber D, Samuelsson B. 5-Lipoxygenase, a key enzyme for leukotriene biosynthesis in health and disease. Biochim Biophys Acta. 2015;1851(4):331-339.

3. Bair AM, Turman MV, Vaine CA, Panettieri RA, Soberman RJ. The nuclear membrane leukotriene synthetic complex is a signal integrator and transducer. Mol Biol Cell. 2012;23(22):4456-4464.
4. Dixon RA, et al. Requirement of a 5-lipoxygenaseactivating protein for leukotriene synthesis. Nature. 1990;343(6255):282-284.

5. Ferguson AD, et al. Crystal structure of inhibitorbound human 5-lipoxygenase-activating protein. Science. 2007;317(5837):510-512.

6. Mandal AK, et al. The nuclear membrane organization of leukotriene synthesis. Proc Natl Acad Sci US A. 2008;105(51):20434-20439.

7. Gerstmeier J, Weinigel C, Rummler S, Rådmark
O, Werz O, Garscha U. Time-resolved in situ assembly of the leukotriene-synthetic 5-lipoxygenase/5-lipoxygenase-activating protein complex in blood leukocytes. FASEB J. 2016;30(1):276-285.

8. Whitacre CC. Sex differences in autoimmune disease. Nat Immunol. 2001;2(9):777-780.

9. Osman M. Therapeutic implications of sex differences in asthma and atopy. Arch Dis Child. 2003;88(7):587-590. 
10. Rubtsova K, Marrack P, Rubtsov AV. Sexual dimorphism in autoimmunity. J Clin Invest. 2015;125(6):2187-2193.

11. Pergola C, et al. ERK-mediated regulation of leukotriene biosynthesis by androgens: a molecular basis for gender differences in inflammation and asthma. Proc Natl Acad Sci US A. 2008;105(50):19881-19886.

12. Pergola C, et al. Testosterone suppresses phospholipase $\mathrm{D}$, causing sex differences in leukotriene biosynthesis in human monocytes. FASEB J. 2011;25(10):3377-3387.

13. Rossi A, Pergola C, Pace S, Rådmark O, Werz O, Sautebin L. In vivo sex differences in leukotriene biosynthesis in zymosan-induced peritonitis. Pharmacol Res. 2014;87:1-7.

14. Poeckel D, Zemski Berry KA, Murphy RC, Funk CD. Dual 12/15- and 5-lipoxygenase deficiency in macrophages alters arachidonic acid metabolism and attenuates peritonitis and atherosclerosis in ApoE knock-out mice. J Biol Chem. 2009;284(31):21077-21089.

15. Haribabu B, Verghese MW, Steeber DA, Sellars DD, Bock CB, Snyderman R. Targeted disruption of the leukotriene $B(4)$ receptor in mice reveals its role in inflammation and plateletactivating factor-induced anaphylaxis. JExp Med. 2000;192(3):433-438.

16. Rathod KS, et al. Accelerated resolution of inflammation underlies sex differences in inflammatory responses in humans. J Clin Invest. 2017;127(1):169-182.

17. Wang SB, Hu KM, Seamon KJ, Mani V, Chen Y, Gronert K. Estrogen negatively regulates epithelial wound healing and protective lipid mediator circuits in the cornea. FASEB J. 2012;26(4):1506-1516.

18. Pettersen D, Davidsson Ö, Whatling C. Recent advances for FLAP inhibitors. Bioorg Med Chem Lett. 2015;25(13):2607-2612.

19. Steinhilber D, Hofmann B. Recent advances in the search for novel 5-lipoxygenase inhibitors. Basic Clin Pharmacol Toxicol. 2014;114(1):70-77.

20. Kim AM, Tingen CM, Woodruff TK. Sex bias in trials and treatment must end. Nature. 2010;465(7299):688-689.

21. Franconi F, Brunelleschi S, Steardo L, Cuomo V. Gender differences in drug responses. Pharmacol Res. 2007;55(2):81-95.

22. Franconi F, Campesi I. Sex and gender influences on pharmacological response: an overview. Expert Rev Clin Pharmacol. 2014;7(4):469-485.

23. Murphy E, Steenbergen C. Sex, drugs, and trial design: sex influences the heart and drug responses. J Clin Invest. 2014;124(6):2375-2377.

24. Israel E, et al. The effects of a 5-lipoxygenase inhibitor on asthma induced by cold, dry air. N Engl J Med. 1990;323(25):1740-1744.

25. Gillard J, et al. L-663,536 (MK-886) (3-[1-(4-chlorobenzyl)-3-t-butyl-thio-5isopropylindol-2-yl]-2,2 - dimethylpropanoic acid), a novel, orally active leukotriene biosynthesis inhibitor. Can J Physiol Pharmacol. 1989;67(5):456-464.

26. Guhlmann A, et al. Prevention of endogenous leukotriene production during anaphylaxis in the guinea pig by an inhibitor of leukotriene biosynthesis (MK-886) but not by dexamethasone. JExp
Med. 1989;170(6):1905-1918.

27. Byrum RS, Goulet JL, Griffiths RJ, Koller BH. Role of the 5-lipoxygenase-activating protein (FLAP) in murine acute inflammatory responses. J Exp Med.1997;185(6):1065-1075.

28. Schaible AM, et al. High capacity for leukotriene biosynthesis in peripheral blood during pregnancy. Prostaglandins Leukot Essent Fatty Acids. 2013;89(4):245-255.

29. Maier TJ, et al. Celecoxib inhibits 5-lipoxygenase. Biochem Pharmacol. 2008;76(7):862-872.

30. Karg EM, et al. Structural optimization and biological evaluation of 2-substituted 5-hydroxyindole-3-carboxylates as potent inhibitors of human 5-lipoxygenase. J Med Chem. 2009;52(11):3474-3483.

31. Hatzelmann A, Fruchtmann R, Mohrs KH, Raddatz S, Müller-Peddinghaus R. Mode of action of the new selective leukotriene synthesis inhibitor BAY X 1005 ((R)-2-[4-(quinolin-2-yl-methoxy) phenyl]-2-cyclopentyl acetic acid) and structurally related compounds. Biochem Pharmacol. 1993;45(1):101-111.

32. Steinbrink SD, et al. Sulindac sulfide suppresses 5-lipoxygenase at clinically relevant concentrations. Cell Mol Life Sci. 2010;67(5):797-806.

33. Fischer L, et al. The molecular mechanism of the inhibition by licofelone of the biosynthesis of 5-lipoxygenase products. Br J Pharmacol. 2007;152(4):471-480.

34. Surette ME, Palmantier R, Gosselin J, Borgeat P. Lipopolysaccharides prime whole human blood and isolated neutrophils for the increased synthesis of 5-lipoxygenase products by enhancing arachidonic acid availability: involvement of the CD14 antigen. J Exp Med.1993;178(4):1347-1355.

35. Nagata M, Saito K. The roles of cysteinyl leukotrienes in eosinophilic inflammation of asthmatic airways. Int Arch Allergy Immunol. 2003;131(Suppl 1):7-10.

36. Söderberg O, et al. Direct observation of individual endogenous protein complexes in situ by proximity ligation. Nat Methods. 2006;3(12):995-1000.

37. Moore AR. Pleural models of inflammation: immune and nonimmune. Methods Mol Biol. 2003;225:123-128.

38. Rao TS, Currie JL, Shaffer AF, Isakson PC. In vivo characterization of zymosan-induced mouse peritoneal inflammation. J Pharmacol Exp Ther. 1994;269(3):917-925.

39. Zhu ML, et al. Sex bias in CNS autoimmune disease mediated by androgen control of autoimmune regulator. Nat Commun. 2016;7:11350.

40. Wang L, Du C, Lv J, Wei W, Cui Y, Xie X. Antiasthmatic drugs targeting the cysteinyl leukotriene receptor 1 alleviate central nervous system inflammatory cell infiltration and pathogenesis of experimental autoimmune encephalomyelitis. J Immunol. 2011;187(5):2336-2345.

41. Johnston NW, et al. Attenuation of the September epidemic of asthma exacerbations in children: a randomized, controlled trial of montelukast added to usual therapy. Pediatrics. 2007;120(3):e702-e712

42. Becker K, Lueddeckens G, Grupe R, Förster W. PAF-induced death in NMRI mice--a suitable shock model for testing new PAF receptor antagonists. Correlation with eicosanoid related substances. Prostaglandins Leukot Essent Fatty Acids. 1993;48(3):265-271.

43. Jawień J, Gajda M, Olszanecki R, Korbut R. BAY $\mathrm{x} 1005$ attenuates atherosclerosis in apoE/LDLR - double knockout mice. J Physiol Pharmacol. 2007;58(3):583-588.

44. Jawien J, et al. Inhibition of five lipoxygenase activating protein (FLAP) by MK-886 decreases atherosclerosis in apoE/LDLR-double knockout mice. Eur J Clin Invest. 2006;36(3):141-146.

45. Lorrain DS, et al. Pharmacological characterization of 3-[3-tert-butylsulfanyl-1-[4-(6-methoxypyridin-3-yl)-benzyl]-5-(pyridin-2-ylmethoxy)1H-indol-2-yl]-2,2-dimethyl-propionic acid (AM103), a novel selective 5-lipoxygenaseactivating protein inhibitor that reduces acute and chronic inflammation. JPharmacol Exp Ther. 2009;331(3):1042-1050.

46. Lorrain DS, et al. Pharmacology of AM803, a novel selective five-lipoxygenase-activating protein (FLAP) inhibitor in rodent models of acute inflammation. Eur J Pharmacol. 2010;640(1-3):211-218.

47. Rouzer CA, Ford-Hutchinson AW, Morton HE, Gillard JW. MK886, a potent and specific leukotriene biosynthesis inhibitor blocks and reverses the membrane association of 5-lipoxygenase in ionophore-challenged leukocytes. J Biol Chem. 1990;265(3):1436-1442.

48. Basavarajappa D, Wan M, Lukic A, Steinhilber D, Samuelsson B, Rådmark O. Roles of coactosin-like protein (CLP) and 5-lipoxygenase-activating protein (FLAP) in cellular leukotriene biosynthesis. Proc Natl Acad Sci U S A. 2014;111(31):11371-11376.

49. Bel ET, et al. MK-886, an effective oral leukotriene biosynthesis inhibitor on antigen-induced early and late asthmatic reactions in man. Am Rev Respir Dis. 1990;141:A3150.

50. Dahlén B, Kumlin M, Ihre E, Zetterström O, Dahlén SE. Inhibition of allergen-induced airway obstruction and leukotriene generation in atopic asthmatic subjects by the leukotriene biosynthesis inhibitor BAYx 1005. Thorax. 1997;52(4):342-347.

51. Gompertz S, Stockley RA. A randomized, placebo-controlled trial of a leukotriene synthesis inhibitor in patients with COPD. Chest. 2002;122(1):289-294.

52. Helgadottir A, et al. Association between the gene encoding 5-lipoxygenase-activating protein and stroke replicated in a Scottish population. Am J Hum Genet. 2005;76(3):505-509.

53. Helgadottir A, et al. The gene encoding 5-lipoxygenase activating protein confers risk of myocardial infarction and stroke. Nat Genet. 2004;36(3):233-239.

54. Hakonarson $\mathrm{H}$, et al. Effects of a 5-lipoxygenaseactivating protein inhibitor on biomarkers associated with risk of myocardial infarction: a randomized trial. JAMA. 2005;293(18):2245-2256.

55. Israel E, Cohn J, Dubé L, Drazen JM. Effect of treatment with zileuton, a 5-lipoxygenase inhibitor, in patients with asthma. A randomized controlled trial. Zileuton Clinical Trial Group. JAMA. 1996;275(12):931-936.

56. Liu MC, Dubé LM, Lancaster J. Acute and chronic effects of a 5-lipoxygenase inhibitor in asthma: a 6-month randomized multicenter trial. Zileuton Study Group. JAllergy Clin Immunol. 1996;98(5 Pt 1):859-871. 